\title{
ENTOMOLOGY
}

\section{Amazing Arachnids}

By Jillian Cowles. 2018. Princeton University Press. 328 pages, 45.00 USD, Cloth, 35.00 USD, E-book.

Amazing Arachnids graced my desk unopened for several weeks while I assumed, based on the title and eye-popping cover, that the book would be a photographic tour of the more spectacular spiders, scorpions, and their kin. That, of course, would have been enough in itself but, when I finally dove into the AMAZING
ARACHNIDS

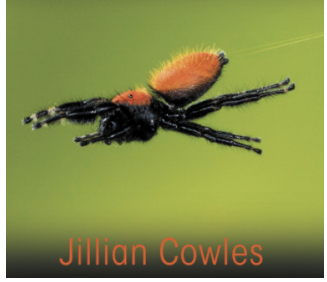
book, I found it to be much, much more. Amazing Arachnids is a thorough treatment of the entire class Arachnida, packed with stunning photos (mostly by the author) and replete with original observations and insights, all stitched together by carefully crafted and densely packed text. I'm not an arachnid specialist, but I found her treatment of even the most obscure arachnid subgroups to be original, readable, and richly detailed.

The first chapter brought me up to speed on basic arachnid structure, biology, and classification in an extensive and exhaustively illustrated introduction, including nice summaries of such disparate subjects as reproductive strategies, fossils, hunting strategies, phylogeny, and vision. The photographic pages covering the "arachnid orders at a glance" (pp. 24-25) were especially useful as an informative snapshot of the orders to be covered in colourful detail in the following pages.

The next nine chapters deal with arachnids other than spiders. Every chapter, even those dealing with relatively obscure groups such as short-tailed whipscorpions and microwhipscorpions, reflects the same level of meticulous scholarship and photographic acumen, with excellent photographs supporting almost every one of the remarkable bits of behaviour and morphology detailed for every group. The author has clearly spent years finding and carefully photographing not only every taxon, but also the details of hunting, habitats, sexual behaviour, and even minute structures such as spermataphores. It is perhaps not surprising that the lively narrative and associated photographs bring scorpions to life and absorb the reader into the history, biology, taxonomy, and structure of these spectacularly armed arachnids. But she succeeds, impressively, in doing the same for the less familiar pseudoscorpions, vinegaroons, short-tailed whipscorpions, tailless whipscorpions, microwhipscorpions, harvestmen, wind spiders, and even ticks and mites. Each order is exposed as beautiful and full of surprises.

The remainder of the book, including somewhat more than half of its 328 pages, covers the spiders. Chapter 11 introduces the order Araneae and offers fascinating detail about sociality, silk, sex, and special behaviours. Oddly, it does not include a section on spider classification or phylogeny. I would have found a summary hierarchical classification or family tree useful to prepare me for the family-by-family coverage in the subsequent chapters. Chapter 12 begins that coverage with the tarantulas, trapdoor spiders, and other "mygalomorphs", including nine richly illustrated pages each for the tarantulas and the trapdoor spiders, and shorter sections for the less familiar families. Chapter 13 covers three families of orb weavers, while Chapter 14 includes half a dozen families of "irregular web builders". One of these families, the black widow family Theridiidae, is clearly a favourite of the author, as her treatment of this group is full of first-hand insight and especially origi- 
nal photos (although this does not mean short shrift for the pholcids and other families discussed in this chapter). Chapter 15 covers the variety of families considered to be crevice weavers, ground weavers, and sheet web builders, with the brown recluse family Sicariidae getting top billing and a particularly readable treatment. Chapter 16 is the most colourful of all, with a good balance of spectacular photos and clear text about everyone's favourite spiders, the Salticidae. The author says that "Jumping spiders have so many pleasing qualities that it would be difficult to decide what is most admirable about these delightful little creatures" (p. 237), but this chapter gives the reader lots on which to base such a decision. The remaining chapters cover the lynx spiders, crab spiders, sand spiders, wolf spiders, fishing spiders, spitting spiders, and the various families of "wandering hunters". As with the rest of this book, these chapters are illustrated with incredible action photos and detailed shots of taxa and structures. Most of the photos are from the spider hotspots of the American Southwest, and this book could serve as a field guide to Arizona arachnids. But this in no way detracts from its value to Canadian naturalists, because it is an exceptionally readable and authoritative review of Arachnida. I consider this an essential volume for any naturalist with any interest in arthropods.

STEPHEN A. Marshall

School of Environmental Sciences, University of Guelph, Guelph, ON, Canada 